\title{
ENTRE VISCOSIDADES POROSAS Y ENTRELAZAMIENTOS. REFLEXIONES SOBRE TECNOCORPORALIDAD EN TIEMPOS DE PANDEMIA
}

\author{
BETWEEN VISCOUS POROSITY AND ENTANGLEMENTS. \\ REFLECTIONS ON TECHNOCORPOREALITY \\ IN TIMES OF PANDEMIC
}

\author{
Myriam Hernández Domínguez \\ Universidad de La Laguna \\ mhernado@ull.edu.es
}

Hace unas décadas, Donna Haraway se preguntaba por qué nuestro cuerpo debe terminar en nuestra piel, o incluir, en el mejor de los casos, otros seres encapsulados por ella ${ }^{1}$. En la pandemia provocada por el coronavirus reverbera esta pregunta. También, el conjunto de reflexiones y conceptos elaborados, en las últimas décadas, por pensadoras posthumanistas, en su intento por reivindicar la necesidad de repensarnos como agentes relacionales imbricados con un conjunto de agencias más que humanas que sobrepasan los límites de nuestra piel. Partiendo de esta premisa pretendo repensar los entrelazamientos que somos, a través de los personajes conceptuales que conforman mi sustrato filosófico, esto es, el conjunto de pensadoras posthumanistas y neomaterialistas que componen el ingenioso abanico del pensamiento posthumano en el siglo XXI. En consonancia con esta propuesta, trataré de poner en común las nociones posthumanistas con nuestra realidad pandémica.

La pandemia ha supuesto una crítica contundente al sujeto liberal, supuestamente independiente, autosuficiente y autónomo. Un cuerpo que podríamos considerar sano, recordemos, no podría respirar sin el conjunto de organismos acuáticos que denominamos fitoplancton, responsables de hasta el $50 \%$ del oxígeno presente en la atmósfera. Ahora bien, si algo ocurre en nuestro cuerpo y nuestra respiración se ve mermada, necesitaremos de un animal humano que nos ayude con una respiración asistida o, en el peor de los casos, con el apoyo de una máquina y su respiración mecánica que nos permitiría continuar respirando, con vida. Criaturas no humanas, naturaleza, tecnología y cuerpos humanos funcionando simbióticamente para mantener la vida. Nuestros tecnocuerpos nos recuerdan nuestros enredos, en tanto 
que entrelazamientos, así como la imposibilidad de una existencia independiente ${ }^{2}$. Esta reflexión sobre cómo nuestra respiración ${ }^{3}$ no es nuestra, sino de otros muchos que también nos conforman, sobre cómo nuestra respiración excede los límites de nuestra piel, sobre cómo nuestros cuerpos no son tan solo nuestros, implica acercarnos a las ideas propuestas por Karen Barad. Por ejemplo, el enredado de las agencia o la intraacción de la que ya ha hablado Mónica Cano en este texto. La propuesta baradiana que insiste en que la materia emerge enredada en un continuo proceso de materialización, a modo de lo que ella denomina «entrelazamientos cuánticos», esto es, como esas partículas que se afectan instantáneamente, a través de cualquier distancia, pudiendo mantenerse conectadas incluso si estuvieran en lados opuestos del universo ${ }^{4}$.

Desde el posthumanismo y a partir de las reflexiones que hemos expuesto en este conjunto de textos podemos pensarnos como criaturas encarnadas, enredadas con y en el mundo dinámico y material que nos atraviesa. Esto nos acerca a un concepto fundamental para el pensamiento posthumanista y neomaterialista contemporáneo, a saber, la transcorporalidad. Stacy Alaimo desarrolla este concepto en su reseñable Exposed. Environmental Politics and Pleasures in Posthuman Times. Esta transcorporalidad cuestiona el sujeto del individualismo humanista que se sabe trascendente, incorpóreo, distanciado del mundo que estudia. El sujeto transcorpóreo se genera a través de y se enreda con sistemas, procesos y acontecimientos biológicos, tecnológicos, políticos, sociales, etc., a diferentes escalas 5 .

La transcorporalidad, al insistir en las inter- e intra- conexiones materiales entre los seres vivos y las sustancias y fuerzas del mundo, niega el excepcionalismo humano al considerar que todas las especies están entrelazadas con lugares concretos y flujos más amplios, quizás, imposibles de rastrear. La transcorporalidad -en la teoría, la literatura, el cine, el activismo y la vida cotidiana- es un modo de ecomaterialismo que desalienta las fantasías de trascendencia e impermeabilidad que hacen del ecologismo una empresa meramente electiva y externa ${ }^{6}$.

\footnotetext{
${ }^{1}$ Haraway, D. (1991). Ciencia, ciborg y mujeres. La reinvención de la naturaleza. Madrid, Cátedra.

${ }^{2}$ Karen Barad propone en su célebre Meeting the Universe Halfway. Quantum Physics and the Entanglement of Matter and Meaning (2007) el concepto de entrelazamiento (entanglement). Se refiere a que estamos enredados con múltiples otros, no al modo de dos entidades separadas, sino como imposibilidad de existir al margen de ellos. Este concepto respalda las propuestas de Haraway en torno a la idea de que los seres no preexisten sus relaciones.

${ }^{3}$ Para una reflexión posthumana de la respiración, véase Gorská, M. (2016). Breathing Matters: Feminist Intersectional Politics of Vulnerability. Universidad de Linköping.

${ }^{4}$ Barad, K. Meeting the Universe Halfway. Quantum Physics and the Entanglement of Matter and Meaning, Londres, Duke University Press, pp. 247-353.

5 Alaimo, S. «Trans-corporality», en Rosi Braidotti y María Hlavajova, Posthuman Glossary, Londres, Bloomsbury Academic, pp. 435-438.

${ }^{6}$ Alaymo, S. Exposed. Environmental politics and pleasures in posthuman times, Londres, University of Minnesota Press, p. 113.
} 
Como el sujeto trans-versal de Braidotti ${ }^{7}$, la transcorporalidad de Alaimo insiste en múltiples cruces, tránsitos y transformaciones. De este modo, pensar la respiración y la pandemia nos hace conscientes de la presencia de otras corporalidades en nuestro cuerpo, de la dependencia de/con otras agencias. Lo animal, lo vegetal, lo tecnológico componen nuestra corporalidad, que va más allá de un simple conglomerado de huesos, piel y órganos exclusivamente humano. La transcorporalidad requiere de un replanteamiento radical de las ontologías y las epistemologías o, siguiendo la terminología baradiana, una reformulación de nuestras ético-onto-epistemologías. De este modo, los cuerpos de la transcorporalidad se reconfiguran como sitios permeables y porosos, en un estado de relación constante. Nos permite superar el olvido de la agencia de la naturaleza para, así, combatir los efectos devastadores de una serie de dualismos oposicionales, basados en una noción de diferencia descaradamente opresora, jerárquica y excluyente. En este caso, centrarnos en la respiración en tiempos de coronavirus nos permite ahondar en la idea de que la respiración mishma es puerta de entrada y salida a lo que puede mantenernos vivos o arrebatarnos la vida. Somos seres vulnerables incluso a los propios organismos que nos componen. La vulnerabilidad es posthumana.

Reflexionar a partir de los futuros posibles y nuevos horizontes de acción el carácter transcoporal e intraactivo de nuestra respiración es el siguiente paso. Repensar nuestra intraacción y enredos para un actuar ético y político que nos proteja. Siendo este "nos» una noción posthumanista de «nosotros», esto es, nunca estrictamente humana. Ser conscientes de cómo nuestra respiración nos conecta con un conjunto de otredades simpoiéticas genera un proceso de desterritorialización respecto a nuestras concepciones antropocéntricas y dualistas. Desde la biología de Lynn Margulis hasta la filosofía de Donna Haraway, el horizonte se construye en torno al desarrollo de un proceso activo, ontológico, epistemológico ético y político, en un planeta donde las especies forman parte de un «devenir con» un mundo en el que no precedemos nuestros entrelazamientos. En este sentido, tiene notable relevancia la noción de viscosidades porosas que desarrolla Nancy Tuana, compartiendo nuestra visión sobre la respiración:

La danza de la agencia entre agentes humanos y no-humanos también sucede a un nivel más íntimo. Los límites de nuestra carne y la carne del mundo en el que estamos son porosos. Mientras que esta porosidad es lo que nos permite prosperar, al respirar el oxígeno que necesitamos para sobrevivir y metabolizar nutrientes de los que emerge nuestra carne, esta porosidad a menudo no discrimina lo que puede matarnos ${ }^{8}$.

7 Para una explicación de la transversalidad en Rosi Braidotti véase su texto Transposiciones. Sobre la ética nómada, Barcelona. Gedisa, 2009. En su famoso texto sobre Lo Posthumano plantea a este respecto que «el desafío para una teoría crítica es crucial: necesitamos visualizar al sujeto como una entidad transversal que abarque lo humano, nuestros vecinos genéticos los animales y la tierra en su conjunto", Braidotti, R. (2015). Lo Posthumano, Barcelona, Gedisa.

${ }^{2}$ Tuana, N. (2008). «Vicous Porosity, Witnessing Katrina», en Stacy Alaimo y Susan Hekman, Material Feminisms, Bloomington, Indiana University Press. 
Nancy Tuana genera su noción de «viscosidad porosa» a partir de la catástrofe del huracán Catrina en Estados Unidos. Fue esta la primera idea que vino a mi mente en cuanto el coronavirus comenzó a ser parte de nuestras vidas. Desde la metafísica de los procesos de Whitehead y las prácticas semiótico-materiales de Haraway, Tuana desarrolla este concepto como una metáfora para entender las relaciones de los seres a través de los cuales somos constituidos. Rechazando el constructivismo social, por estar contaminado con un quiasmo entre naturaleza y cultura, Tuana trata de reconocer la agencia de la materialidad y la porosidad de las entidades, admitiendo la «robusta porosidad» entre fenómenos que desestabilizan cualquier esfuerzo por determinar una división de la naturaleza. Si, hablando del Catrina, Tuana dice que «no es posible distinguir entre lo puramente humano de lo puramente natural, no sabemos hasta qué punto la acción humana (como la búsqueda de combustibles fósiles) pudo motivar o facilitar un fenómeno así,» considero que, años más tarde, algo muy parecido podríamos comentar de la crisis pandémica que vivimos.

Ampliar, entonces, los marcos éticos y agencias pasa por pensarnos a nosotras mismas es un reto, no solo para respirar con más consciencia, sino para percatarnos de cómo lo tecnológico, animal o vegetal nos conforma a través de y gracias a la porosidad de nuestra carne. Como explica Paul B Preciado en Sopa de Wuhan, «seguir con vida, mantenernos vivos como planeta frente al virus, pero, también, frente a lo que pueda suceder, significa poner en marcha formas estructurales de cooperación planetaria. Como el virus muta, si queremos resistir a la sumisión, nosotros también debemos mutar».

Respirar y, en concreto, respirar en tiempos de coronavirus, implica saberse fruto, parte y proceso de una multiplicidad de intraacciones y cambios que, siguiendo a Glissant, siempre serán con-cambios imprevisibles, criollizaciones. Las corporalidades encarnadas de la Tierra se coconstituyen en un devenir conjunto entre la vulnerabilidad posthumana y afirmativa que les son propias. 